\title{
A clash of theoretical orientations: Demand characteristics and the attraction paradigm
}

\author{
KAREN B. NICHOLAS and HUGH McGINLEY \\ University of Wyoming, Laramie, Wyoming 82701
}

\begin{abstract}
One hundred and seventy-five female students viewed a videotaped presentation of a female stranger who expressed opinions about topical areas that were correlated with but not the same as the topics of items to which the subjects had responded on an attitude questionnaire. The results showed that both judged aware and judged unaware subjects responded more positively to the stranger and inferred more similar interests if she was attitudinally similar to them. Since verbalized awareness of attitudinal similarity is not a necessary condition in a reinforcement point of view of interpersonal attraction, the overall results of the study support such a viewpoint.
\end{abstract}

Byrne (1971), in concert with Newcomb's (1959, 1961) proposal that interpersonal attraction is a function of the rewards that individuals incur in an interaction, has reported an empirical relationship between attitude similarity and interpersonal attraction. One of Byrne's common experimental designs is to have a subject complete an attitude questionnaire and then, at a future date, be exposed to a copy of the same attitude questionnaire that had been completed by another person, a stranger. After reading the stranger's questionnaire (which is marked in such a way as to be either similar or dissimilar to the subject's marking of the questionnaire), the subject rates the stranger on the Interpersonal Judgment Scale (IJS). Experiments of this design invariably yield the result that subjects are more attracted to strangers who hold attitudes similar to their own than to strangers who hold dissimilar attitudes. Byrne and others have obtained similar results when modifications of the basic design were used (see review by Byrne \& Griffitt, 1973).

Most of the discussion of Byrne's (1971) interpersonal attraction theory concerns either the theoretical approaches of other philosophical orientations that may explain the attitude similarity/interpersonal attraction phenomenon or a demand-awareness explanation of the subject's indicated attraction toward the stranger.

Byrne's (1971) theory and other reinforcement theories of attraction (e.g., Lott \& Lott, 1972) evoke a classical conditioning model in order to explain how positive or negative affect becomes associated with a stranger. The model assumes that any stimulus that is reinforcing can serve as an unconditioned stimulus (UCS) that elicits an implicit affective response (ur). The model holds that a neutral person/stimulus (CS) who is associated with attitude agreement will, thereafter, elicit a conditioned implicit affective response (cr) and that the cr mediates an overt evaluative response toward the stimulus/person. Furthermore, the strength of the cr, as implied by the overt response of attraction, is a positive function of the intensity of the UCS, that is, the proportion of similar attitudes to dissimilar attitudes and the saliency of the attitudes that had been associated with the stimulus/person (CS). The model does not hold that the subject must be verbally aware of the association between the CS and the UCS in order for the conditioning to occur; that is, the subject does not have to be able to verbalize the reinforcement contingency, attitude similarity. This awareness is called contingency awareness (McGinley \& Layton, 1973).

Kaufman and Zener (1967) suggest that subjects in attitude similarity/interpersonal attraction studies might be responding to the cognition that a stranger who is similar to them in attitude should be liked. For instance, the subject's rating of the stranger may be either the result of a drive for cognitive consistency (the person is similar to me; therefore I should like him) or the result of the demands placed on the subjects by the design of the experiment (I am similar to the stranger; therefore it is expected that I should rate the stranger positively). The latter interpretation is consistent with investigators who caution that artifactual effects may result from the demand characteristics of an experiment (Orne, 1969; Page, 1974).

Neither a reinforcement model nor a cognitive balance model of attitude similarity/interpersonal attraction effects is supported by a measurement of interpersonal attraction that is no more than the result of demand characteristics. For this reason, it is important to ascertain empirically the effects of demand characteristics in attitude similarity/interpersonal attraction studies. Also, it is of theoretical importance to establish whether interpersonal attraction toward a stranger may be the consequence of attitude similarity in the absence of verbalized contingency awareness (the reinforcement model) or if attitude similarity effects only occur following contingency awareness (the cognitive model).

The question of the possible role of demandcharacteristic effects in interpersonal attraction studies has been experimentally addressed by investigators who have concluded that, although there may be a demand- 
characteristics effect in attitude similarity/interpersonal attraction studies, there is reason to believe that the interpersonal attraction between people is at least partially the consequence of their similarity of attitudes (Lamberth \& Byrne, 1971; Murray \& McGinley, 1972). It is less clear, however, whether the attraction toward others that follows a manipulation of attitude similarity occurs only with people who are verbally aware of their similarity of attitude with the others (McGinley, 1980). In an attempt to clarify the role of verbalized contingency awareness in an interpersonal attraction study, McGinley and Reiner (1979) used correlated forms of an attitude questionnaire that seemingly reduced the frequency of subjects who reported contingency awareness. In this study, subjects perused 10-item attitude questionnaires that supposedly had been filled out by strangers and then rated the interpersonal attraction of the strangers. The subjects were either very similar $(90 \%)$ or very dissimilar $(10 \%)$ to the strangers, with the proportion of attitude similarity being derived from the subjects' responses to 10 items of a 75 -item questionnaire that they had completed 2 weeks before. Although the 10 matched items of the two questionnaires correlated well, they were not the same items per se.

In order to investigate further the relationship between verbalized awareness of attitude similarity and interpersonal attraction, the present study employed the correlated-item procedure for manipulating attitude similarity. The standard stranger procedure of manipulation was used: Subjects viewed videotapes of a stranger who expressed personal beliefs during an interview (Hodges \& Byrne, 1972). Both the IJS and an interest similarity measure were used to measure the effect of attitude similarity, and an extensive postexperimental questionnaire was used to assess contingency awareness.

\section{METHOD}

\section{Subjects}

The subjects were 186 female undergraduate psychology students at the University of Wyoming. Six were eliminated from the statistical analysis because they did not complete the forms they were given, and five subjects were eliminated because they personally knew the stranger/model who appeared in the experiment.

\section{Materials}

Four videotape presentations were prepared that used the same female stranger. In each presentation, the stranger answered an identical set of 10 questions that were designed to measure attitudes on a variety of topics; however, her answers were different in each of the four presentations. The answers were designed to be similar to the answers of a typical University of Wyoming female undergraduate (Presentation 1), to be less similar to the average student (Presentation 2), to be dissimilar to the average student (Presentation 3), or to be quite dissimilar to the average student (Presentation 4). The four videotapes were used in an effort to obtain a range of attitude similarity scores between the subjects and the stranger.

Each subject completed five forms (one of the forms, the interest inventory, was completed twice). First, she completed a 10-item attitude questionnaire that was adopted from McGinley and Reiner (1979). This questionnaire consisted of items that were correlated with the questions to which the stranger responded in her videotape presentation.

The subject then completed an interest inventory that was devised by administering a 40 -item interest questionnaire to female students and then selecting the 15 items that had the greatest diversity of answers. The questions were concerned with the likes and dislikes of different activities and subjects.

The next scale that was completed was the IJS (adapted from Byrne, 1971). It consisted of five items designed to measure a subject's opinions about a stranger. The questions related to the stranger's intelligence, the stranger's knowledge of current events, personal feelings (degree of liking), desire to work together, and the stranger's personal adjustment. The subject's responses to the "liking" and "working together" items were summed to form a single measure of attraction.

The next form that was completed was a postexperimental questionnaire. The questionnaire was used in an attempt to measure demand characteristics that may have been associated with the experimental procedure. It consisted of 11 questions set up in a funnel approach. Only one question was printed on a page, and subjects were instructed to answer the questions in order without referring to previously answered questions. The key questions of the questionnaire were: "What was the purpose of the experiment?", "Do you think the experiment involved something other than what the experimenter told you? If so, what?", "How do you think the experimenter expected you to rate the person whom you viewed on the videotape?", "Do you think the experimenter expected you to respond in a consistent direction (positive or negative, for example) when you judged the person's intelligence, adjustment, etc.? If so, in what direction? Why?", and "Why were you asked to fill out a copy of the interest survey in the manner that you thought the person would fill it out?"

The last form filled out by the subjects was a printed version of the attitude questionnaire that the model on the videotape had answered orally. The subjects were asked to recall how the stranger had answered the questions by completing the questionnaire in a manner consistent with what the stranger had said.

\section{Procedure}

Two experimental rooms were used. Against the wall opposite the only door was a table on which there was a 21 -in. television monitor. There were two chairs in each room, one on either side of the door and both facing the monitor. There were four female experimenters, each of whom tested about one-fourth of the subjects. Each subject was greeted by the experimenter in a waiting room and was taken to one of the experimental rooms, where she was seated in front of the television monitor. The subject was first asked to complete the attitude questionnaire and then to complete the interest inventory. Each form was collected as soon as the subject completed it. The subject was then handed a blank questionnaire containing the questions the stranger would be answering and was told to listen carefully to the videotaped presentation. The subjects were told that the experimenters were interested in the impression that the interviewee left with them and that the forms that they were to fill out would help to measure this impression.

Following the videotaped presentation, the blank questionnaire was collected and the subject was instructed to (1) complete the IJS, (2) fill out the interest inventory as she thought the woman on the videotape would complete it, (3) complete the postexperimental questionnaire, and (4) complete the blank questionnaire form as she recalled the stranger had answered it. Each completed form was collected before the next form was given to the subject.

The four taped presentations of the stranger were reproduced on a master videotape with pauses between each presentation. The videotape was started with the first presentation for the first subject. The tape was continued in sequence for the next three subjects, so that by the fourth presentation, each subject had viewed a different presentation. The tape was then rewound and the sequence was repeated. 


\section{Scoring}

Attitude questionnaire. Each question on the attitude questionnaire offered eight possible answers ranging from "absolutely in favor" of to "absolutely opposed" to the topic under consideration, with four of the choices in a positive direction and four in a negative direction. In scoring, the most positive answer was scored as 1 , and the most negative response was scored as 8 .

To compare the subject's attitudes with those of the stranger, an algebraic sum of the differences on all 10 questions was computed by assigning a positive value to each interval of difference if the stranger's answer was a stronger preference in the same direction as the subject's. It was given a negative value if it was a lesser preference in the same direction or if it was in the opposite direction. The difference score between the subject's and stranger's attitudes was used as the index of attitude similarity/ dissimilarity, with lower values indicating similarity. The difference score between the subject's recall of what the stranger said and what the stranger actually said was used as an indication of how carefully the subjects had listened to the stranger, as well as a secondary index of attitude similarity.

Interpersonal judgment scale. The IJS was scored by assigning a value of 1 to the most positive choice on each question and a value of 7 for the most negative choice. The measure of attraction was derived by summing the scores for the questions concerning liking and working together. This was the primary measure of attraction. A positive and linear relationship was expected between attitude similarity and interpersonal attraction.

Interest inventory. The interest inventory was scored by assigning values from 1 to 5 to each of its 15 items, with a value of 1 indicating high interest. The scoring system for similarity of interests was the same as that used for attitude similarity, the projected scale values for the stranger were compared with the subject's scale values. The interest inventory was used as a secondary measure of the effect of attitude similarity. It was reasoned that the subjects who were similar in attitude to the stranger would be more attracted to the stranger. Theoretically, this positive feeling toward the stranger would cause the subjects to view the stranger as similar in interest to them. The measure, of course, is vulnerable to subject awareness effects. For instance, if subjects verbalize that the stranger is attitudinally similar or dissimilar to them (contingency aware), then they might generalize this sameness or difference to interests. Subjects should, however, be able to verbalize such a generalization when they fill out the postexperimental questionnaire.

Postexperimental questionnaire. The postexperimental questionnaires were read independently by two judges who assigned each subject to one of three categories: unaware, contingency aware, or demand aware. Subjects who were judged to be unaware answered none of the questions in a manner that was judged to indicate that they were aware of the experimental manipulations. Subjects who were judged to be contingency aware recognized the similarity or dissimilarity of their answers on the attitude questionnaire to those attitudes that were orally expressed by the stranger. Those subjects judged to be demand aware also recognized the similarity/dissimilarity of attitudes but went beyond this observation and commented that they felt that they were expected to respond favorably to a similar person or unfavorably to a dissimilar one or that they were to mark that the stranger had interests similar to their own.

The judges agreed on $160(91 \%)$ of the questionnaires. The remaining 15 questionnaires were read by a third judge and were categorized by the majority judgment. The judgments were used to separate aware and unaware subjects in the analyses of the attraction and interest data.

\section{RESULTS}

The results of the experiment, as summarized in Table 1, are in accord with the attitude similarity/ interpersonal attraction hypothesis. The data analyses showed that interpersonal attraction correlated positively with the degree of attitude similarity between subjects and the stranger. The results were similar both for attitude similarity to the actual stranger and for attitude similarity when the stranger's attitudes were defined by the attitudes as they were recalled by the subjects. The correlation between the two indexes of attitude similarity was high $[\mathrm{r}(173)=.88, \mathrm{p}<.001]$.

The use of the interest inventory as a measure of the effect of attitude similarity also produced significant results. The correlation coefficient between the attitude similarity score and the interest similarity score was positive and significant both when attitude similarity was based on the stranger's verbalization of her opinions and when it was based on the subject's recall. Also, there was a significant, positive relationship between interest similarity and attraction.

According to the judges, 26 of the subjects (15\%) were aware of the experimental manipulation (contingency aware) and knew how the experimenter expected them to respond (demand aware). An additional 13 subjects (7\%) were judged to be contingency aware but not demand aware. The remaining 136 subjects (78\%) were judged to be unaware. With regard to the overall

Table 1

Pearson Correlation Coefficients for All Categories of Subjects: Difference Score Data

\begin{tabular}{|c|c|c|c|c|c|c|c|c|c|c|c|}
\hline \multirow[b]{3}{*}{ Subjects } & \multirow[b]{3}{*}{$\mathrm{n}$} & \multicolumn{4}{|c|}{$\begin{array}{c}\text { Attraction and } \\
\text { Attitude Similarity }\end{array}$} & \multicolumn{4}{|c|}{$\begin{array}{l}\text { Interest Similarity and } \\
\text { Attitude Similarity }\end{array}$} & \multirow{2}{*}{\multicolumn{2}{|c|}{$\begin{array}{c}\text { Interest Similarity } \\
\text { and Attraction }\end{array}$}} \\
\hline & & \multicolumn{2}{|c|}{ Actual } & \multicolumn{2}{|c|}{ Recalled } & \multicolumn{2}{|c|}{ Actual } & \multicolumn{2}{|c|}{ Recalled } & & \\
\hline & & $\mathbf{r}$ & $\mathrm{p}^{*}$ & $\mathbf{r}$ & $\mathrm{p}^{*}$ & $\mathrm{r}$ & $\mathrm{p}^{*}$ & $\mathbf{r}$ & p* & $\mathbf{r}$ & p* \\
\hline Total & 175 & .29 & .001 & .31 & .001 & .24 & .001 & .26 & .001 & .41 & .001 \\
\hline Unaware & 136 & .28 & .001 & .30 & .001 & .23 & .01 & .25 & .01 & .41 & .001 \\
\hline Contingency Aware & 39 & .35 & .05 & .38 & .05 & .31 & .06 & .34 & .05 & .44 & .005 \\
\hline Demand Aware & 26 & .47 & .025 & .53 & .01 & .17 & n.s. & .25 & n.s. & .32 & n.s. \\
\hline
\end{tabular}

Note-Actual attitude similarity refers to the difference between the subject's written questionnaire and what the stranger actually said; recalled attitude similarity refers to the difference between the subject's written questionnaire and what she recalled that the stranger had said. The contingency-aware category included the 26 subjects who were judged as demand aware.

${ }^{*} p<$ value given. 
effect of attitude similarity, the correlation coefficients between attraction and contingency or demand awareness were near zero. Subjects in each of the groups of contingency aware, demand aware, and unaware showed increased attraction toward a similar stranger, and there were positive relationships between the interest similarity scores and the subjects' attraction toward the stranger for subjects who were judged as unaware or as contingency aware. Also, all but the demand-aware subjects showed a positive and linear relationship between attitude similarity and interest similarity. With the exception of this last relationship, there appeared to be a trend for the correlations to be higher for aware subjects than for unaware subjects. This trend, however, was not significant. None of the differences between correlation coefficients, within a measure, was significant.

\section{DISCUSSION}

The results strongly suggest that although demandcharacteristic effects are probably confounded with the commonly reported attitude similarity/interpersonal attraction relationship, the relationship is not an artifact of demand characteristics per se. Also, the theoretical position that is held by reinforcement theorists was supported, in that the subjects' verbalizations of the reinforcement contingency between their attitudes and the attitudes of the stranger was not needed for them to respond to the dependent measures in a manner consistent with a reinforcement hypothesis. These measures consisted of the commonly used IJS and the newly devised interest inventory. Not only did the subjects mark that they were more attracted to an attitudinally similar stranger than to an attitudinally dissimilar stranger, but also subjects who were similar to the stranger in attitude projected that the stranger would be similar to them in interests. Inasmuch as this relationship held for subjects who were judged unaware, it seems unlikely that the effect was the result of personal logic, "the stranger was similar to me in attitude, so she should have similar interests." At the same time, it seems likely that the positive emotional state that is purported by reinforcement theorists to be the result of reinforcement (in this case, attitude similarity) mediated the reported interest similarity. That is, the interest data provided a new source of support for the reinforcement point of view of interpersonal attraction.

Another aspect of the results that is worthy of attention is the lower than usual percentage of subjects who were judged aware. Using the more traditional attitude questionnaire procedure and an awareness questionnaire that was essentially the same as the one used in the present study, McGinley and Reiner (1979) found that $47 \%$ of their subjects were judged to be contingency aware (an additional 13\% were judged as "maybe aware"). However, when they used their correlated questionnaire technique, the subjects judged to be contingency aware dropped to $31 \%$ (with an additional $17 \%$ being judged as maybe aware). In the present study, using both a correlated questionnaire technique and the videotaped presentation of the stranger, only
$22 \%$ of the subjects were judged to be contingency aware (the maybe-aware category was not used). These results strongly suggest that the combination of the video presentation of the stranger and the correlated questionnaire procedure effectively reduced the subjects' verbalized awareness of attitudinal similarities or dissimilarities between themselves and the stranger. The importance of this finding is: (1) that there is little reason to assume that the experimentally established relationship between attitude similarity and interprersonal attraction is an artifact of demand characteristics, and (2) that a subject does not have to be verbally aware of the attitude similarity between herself or himself and a stranger before rating an attitudinally similar other as interpersonally attractive or before inferring that the other person holds interests similar to her or his own.

\section{REFERENCES}

Byrne, D. The attraction paradigm. New York: Academic Press, 1971.

Byrne, D., \& Griffitt, W. Interpersonal attraction. Annual Review of Psychology, 1973, 24, 317-336.

Hodges, L., \& BYRNe, D. Verbal dogmatism as a potentiator of intolerance. Journal of Personality and Social Psychology, 1972, 21, 312-317.

Kaufman, H., \& Zener, L. Perceived similarity and liking as functions of manipulated similarity and subjective social favorability. Psychonomic Science, 1967, 9, 75-76.

Lamberth, J., \& Byrne, D. Similarity-attraction or demand characteristics. Personality, 1971, 2, 77-91.

LoTT, A. J., \& LoTT, B. E. The power of liking: Consequences of interpersonal attitudes derived from a liberalized view of secondary reinforcement. In L. Berkowitz (Ed.), Advances in experimental social psychology. New York: Academic Press, 1972.

McGinley, H. A test for artifactual effects in an attitude similarity/interpersonal attraction study. Bulletin of the Psychonomic Society, 1980, 16, 137-139.

McGinley, H., \& LAYton, B. Conditioning of evaluative meaning without contingency or demand awareness. Journal of General Psychology, 1973, 89, 81-90.

McGinley, H., \& Reiner, M. Contingency awareness and interpersonal attraction. Bulletin of the Psychonomic Society, 1979, 13, 175-178.

MurRay, R., \& McGinley, H. Looking as a measure of attraction. Journal of Applied Social Psychology, 1972, 2, 267-274.

Newcomb, T. M. Individual systems of orientation. In S. Koch (Ed.), Psychology: A study of a science (Vol. 3). Formulation of the person and the social context. New York: McGraw-Hill, 1959.

Newcomв, T. M. The acquaintance process. New York: Holt, Rinehart \& Winston, 1961.

Orne, M. F. Demand characteristics and the concept of quasicontrols. In M. Rosenthal \& R. L. Rosnow (Eds.), Artifact in behavioral research. New York: Academic Press, 1969.

PAGE, M. M. Demand characteristics and the classical conditioning of attitude experiment. Journal of Personality and Social Psychology, 1974, 30, 468-476.

(Received for publication October 29, 1981.) 